\title{
Effect of Molding Condition on Waviness Profile of GFRP Composites in Compression Molding
}

\author{
J.W. KIM ${ }^{a}$, H.S. KIM ${ }^{b}$ AND D.G. LEE ${ }^{c, *}$ \\ ${ }^{a}$ NGV R\&D Center, Gwangju Technopark, Chum-Dan Gwagiro 333, Buk-gu \\ Gwangju 500-706, South Korea \\ ${ }^{b}$ Department of Advanced Parts and Materials Engineering, Chosun University Graduate School \\ 375 Seosuk-dong, Dong-gu, Gwangju 501-750, South Korea \\ ${ }^{c}$ Department of Mechatronics Engineering, Chosun University, 375 Seosuk-dong, Dong-gu \\ Gwangju 501-750, South Korea
}

\begin{abstract}
During compression molding of glass fiber reinforced plastic composites, annealing and quenching experiment is conducted by changing pre-heating and cooling method. As results, major cause of unevenness that affects waviness profile (winding) is the shrinkage of matrix during holding and cooling process. Waviness profile of the surface on molding in glass fiber reinforced plastic composites will be lower when holding pressure load is higher, mold temperature is lower during demolding, and cooling rate is slower. In addition, surface roughness of moldings is depending on holding pressure load compared with mold temperature. According to molding condition of glass fiber reinforced plastic composites, waviness profile of surface can be quantitatively estimated using the proposed equation.
\end{abstract}

DOI: 10.12693/APhysPolA.123.337

PACS: 81.05.Lg, 81.05.Qk, 88.30.mj

\section{Introduction}

Recent automobile industry should satisfy driving performance, durability, and environmental regulation along with the advanced equipment for safety and various customer demands. Exhaust gas from automobile, which is considered the one of major causes for global warming, needs to be cut down, and fuel mileage improvement is the most widely adopted around automobile industries. The most efficient way to improve fuel mileage is the light-weight of structural member in automobile body. Glass fiber reinforced plastic (GFRP) composites have not only specific strength $(E / \rho)$, specific stiffness $(S / \rho)$ but also light-weight, formability, productivity, etc.

Currently, GFRP composites are employed in internal and external components in automobile, such as bumper beam, front end, door, seat structure, truck steps, etc. To apply light weight material into automobile component, the corresponding material characteristics, reliability, molding condition, etc. should be established, and the relevant researches on GFRP composites have been actively conducted.

Lee et al. reported that fiber orientation is not influenced by mold closing speed and molding temperature, but depends on compression ratio during compression molding of GFRP composites. In addition, the separation and orientation is not independent, and has the close relationship even for commercially available GFRP composites [1-5].

Composition ratio for plastic composite by resin type, which was adopted for automobile, is about $85 \%$ for ther-

\footnotetext{
*corresponding author
}

moplastic and $15 \%$ for thermosetting plastics. GFRP composites for pressing process are a laminate of matrix sheet and glass fiber mat, and it is available as secondary product. Molding method for GFRP composites is press molding by heating the blank after cut into desired dimension.

As the defect that hinders the application of GFRP composites is waviness profile (winding). On the surface of moldings, there are many types of unevenness such as spherulite, fiber projection, crack, fiber exposure, micro-weldline, pinhole, etc. Compared with homogeneous matrix, GFRP composites shows higher waviness profile. For this reason, the application of GFRP composites is limited. Even though of this problem, study on the identification of surface defect formation for GFRP composites and its improvement is limited [6,7]. In this study, waviness profile is measured for GFRP composites, which is fabricated with various molding conditions, and the relationship between defect size and molding condition is evaluated.

\section{Experimental methods and molding conditions}

In this study, shape of moldings is selected to be rectangular shaped plate with the same thickness to remove torsion or bending characteristics for the investigation on the impact of molding condition on waviness profile. Test material is fixed as single type of material, and molding condition is changed accordingly. As test material, GFRP composites with polypropylene resin and glass fiber reinforcement (Japan, P4038-B Sheet) is used. In addition, fiber content is fixed to $40 \mathrm{wt} \%$. 
Table I shows the basic properties of GFRP composites. Specific weight for glass and resin is $2.55 \mathrm{~g} / \mathrm{cm}^{3}$ and $0.9 \mathrm{~g} / \mathrm{cm}^{3}$, respectively. Test specimen for GFRP composites is cut into $60 \mathrm{~mm}$ (width) $\times 80 \mathrm{~mm}$ (length) $\times$ $3.8 \mathrm{~mm}$ (thickness). General molding method for GFRP composites is hydraulic hot press for high temperature compression flow molding, but material flow generates the separation of matrix and orientation of fiber. In this study, impact of separation and orientation is removed by adopting the same size of blank and molding part. Therefore, size of blank is set to be the same as mold cavity, and material has the restricted flow.

Material properties of GFRP composites (P4038-B Sheet).

TABLE I

\begin{tabular}{c|c|c|c}
\hline \hline Properties & Value & Properties & Value \\
\hline specific gravity & 1.19 & filament diameter $[\mu \mathrm{m}]$ & 22 \\
void content [\%] & $3-5$ & filament number [ea] & 60 \\
sheet weight $\left[\mathrm{N} / \mathrm{mm}^{2}\right]$ & $44 \pm 2$ & fiber length [mm] & 55
\end{tabular}

Press for compression molding is hydraulic hot press with load control. If pre-heating of blank is needed according to test condition, IR heater is used. Mold is consisted of punch and die, and the relevant thermocouple is attached. Heating of mold is done through rod heater, and hole for cooling water circulation is made on punch and die. Holding pressure load is measured via load sensor for resistance heat gauge with $4 \mathrm{~mm}$ diameter pin. For mold temperature, it is measured from $1 \mathrm{~mm}$ above from cavity surface using thermocouple $(\emptyset 1.0 \mathrm{~mm})$. Load sensor includes the amplifier, and thermocouple is connected to data digitizer for data collection and control with computer.

Process for compression molding of GFRP composites is consisted of pre-heating, filling, holding/cooling, and demolding. In this study, conditions for pre-heating and cooling are changed to be annealing and quenching.

First, annealing experiment is conducted through placing material into mold cavity, and mold itself is heated up to molding temperature. After compression molding, mold and its part is cooled together. This method shows the same temperature for material and mold during the molding process. Therefore, not only test material but also mold is cooled together, and shows the slow cooling speed. Correspondingly, material is cooled slowly. Molding condition for GFRP composites in annealing experiment is shown in Table II. Molding temperature and speed is set to be constant and holding pressure load and mold temperature at demolding is changed.

TABLE II

Molding condition of annealing experiment.

\begin{tabular}{c|c|c|c}
\hline \hline $\begin{array}{c}\text { Molding } \\
\text { temp. }\end{array}$ & $\begin{array}{c}\text { Molding } \\
\text { velocity }\end{array}$ & $\begin{array}{c}\text { Holding pressure } \\
\text { load }\end{array}$ & $\begin{array}{c}\text { Demolding } \\
\text { temp. }\end{array}$ \\
\hline $173^{\circ} \mathrm{C}$ & $13 \mathrm{~mm} / \mathrm{s}$ & $\begin{array}{c}50,100,150, \\
200,250,300 \mathrm{kN}\end{array}$ & $\begin{array}{c}40,60, \\
80,100{ }^{\circ} \mathrm{C}\end{array}$
\end{tabular}

Second, quenching experiment is conducted through placing GFRP blank, which is heated and expanded by
IR heater, into mold cavity in low temperature than recrystallization temperature of material. After compression molding, material is cooled. It is the same method that is utilized in the production environment. Through this process, material near to mold wall will be quenched, and it features very short molding cycle. Molding condition for GFRP composites is shown in Table III. For quenching experiment, blank temperature, molding speed, and holding pressure time is set to be constant, and mold temperature and holding pressure load is changed.

TABLE III

Molding condition of quenching experiment.

\begin{tabular}{c|c|c|c}
\hline \hline $\begin{array}{c}\text { Blank } \\
\text { temp. }\end{array}$ & $\begin{array}{c}\text { Molding } \\
\text { velocity }\end{array}$ & $\begin{array}{c}\text { Holding pressure } \\
\text { load }\end{array}$ & $\begin{array}{c}\text { Mold } \\
\text { temp. }\end{array}$ \\
\hline $200^{\circ} \mathrm{C}$ & $13 \mathrm{~mm} / \mathrm{s}$ & $\begin{array}{c}50,100,150, \\
200,250,300 \mathrm{kN}\end{array}$ & $\begin{array}{c}40,60, \\
80,100{ }^{\circ} \mathrm{C}\end{array}$
\end{tabular}

\section{Measurement method for waviness profile}

As shown in Fig. 1, degree of surface roughness on moldings in $A-B$ of cross-section can be denoted as waviness profile. For $40 \mathrm{wt} \%$ of glass fiber content of moldings, thinner cross-section is achieved where matrix is predominant over glass fiber due to the greater difference of shrinkage ratio in unit volume of matrix. On the contrary, thicker cross-section is found where glass fiber is predominant. Therefore, waviness profile originates from the difference in shrinkage ratio and inhomogeneity between matrix and glass fiber.
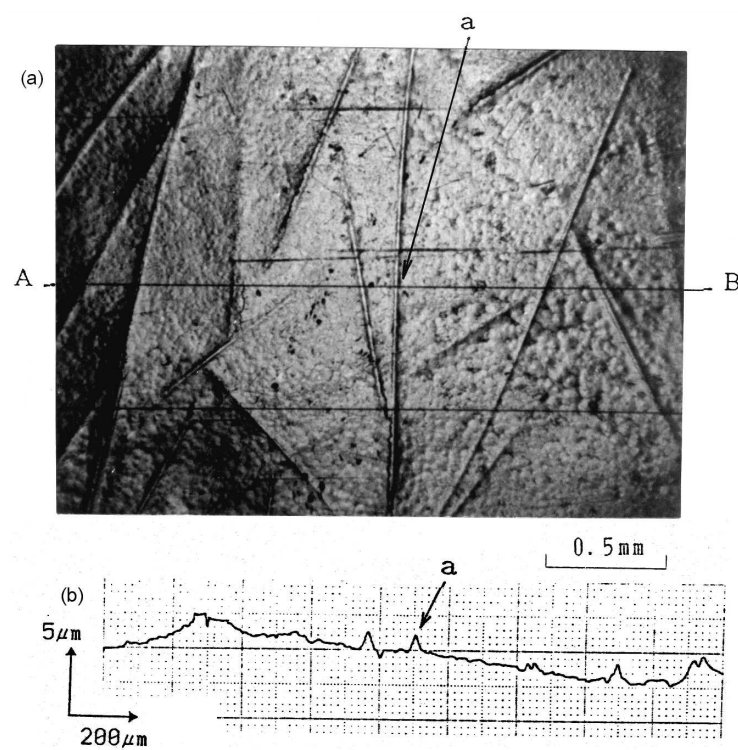

Fig. 1. Fiber projection: (a) micrograph, (b) section $A B$.

Defect at the surface of moldings during compression molding of GFRP composites is called surface defect, 
and it is appreciated as irregular waviness profile. Cross-section of surface unevenness in moldings can be divided into shape tolerance, waviness profile, and surface roughness.

In this study, precision in moldings is not treated, and shape tolerance is neglected. Item that is related to the appearance of moldings is surface roughness and waviness profile. However, surface roughness is relatively small compared with waviness profile, and it can be negligible. Measurement of waviness profile on moldings is made with 2-dimensional surface profiler (Japan, Surfcom 570A). This measurement equipment can evaluate surface profile with automated inclination correction.

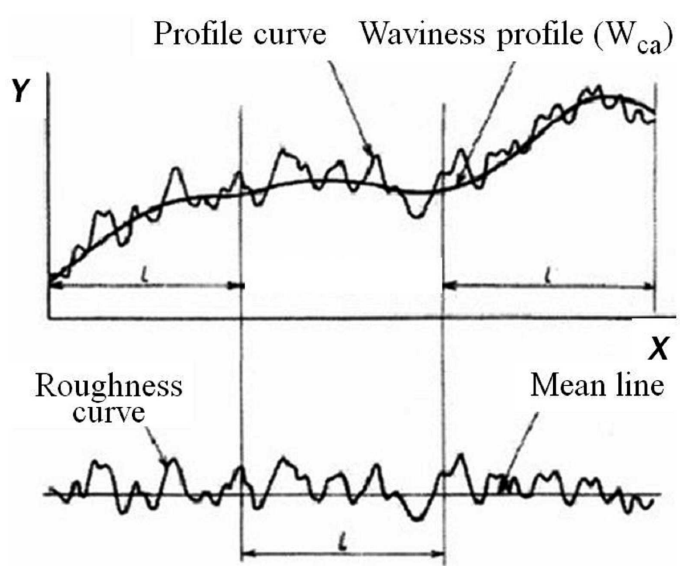

Fig. 2. Profile curve, waviness profile, and roughness curve.

Waviness profile for irregular surface unevenness is shown in Fig. 2. Waviness profile can be obtained by removing the short and long component in profile curve, and the corresponding waviness profile curve can be extracted. This extraction curve is free from shape tolerance effect, such as bending. The corresponding equation for waviness profile ( $\left.W_{\mathrm{ca}}\right)$ is written as Eq. (1) for the unit of $\mu \mathrm{m}$

$$
W_{\text {ca }}=\frac{1}{l}=\int|f(x)| \mathrm{d} x .
$$

Cutoff value that is used for the measurement of $W_{\text {ca }}$ is $0.8-8 \mathrm{~mm}$, and its measurement length is $30 \mathrm{~mm}$. According to the characteristics of GFRP composites, variation of measurement is significant, and measurements are conducted in 10 times for length direction. The average value is adopted.

To investigate the surface state of mold that is used for experiment, waviness profile of mold is measured. As results, waviness profile, $W_{\text {ca }}$, is measured to $0.2 \mu \mathrm{m}$. In addition, surface state of mold is checked to confirm the transference to molded polypropylene part with $100 \mathrm{kN}$ of holding pressure load and $80^{\circ} \mathrm{C}$ of mold temperature at demolding. The corresponding waviness profile, $W_{\text {ca }}$, is $0.21 \mu \mathrm{m}$. When the similar value for homogeneous polypropylene shows the similar one for the mold, the surface state of mold is well transferred to the moldings.

\section{Results and discussion}

At the actual production environment for GFRP composites, blank at $200{ }^{\circ} \mathrm{C}$ is placed into the mold at $40-80^{\circ} \mathrm{C}$, and it is compressed with about $15-20 \mathrm{MPa}$ of pressure. After quenching, it is demolded. In this study, the same molding condition as production environment is adopted as annealing and quenching.

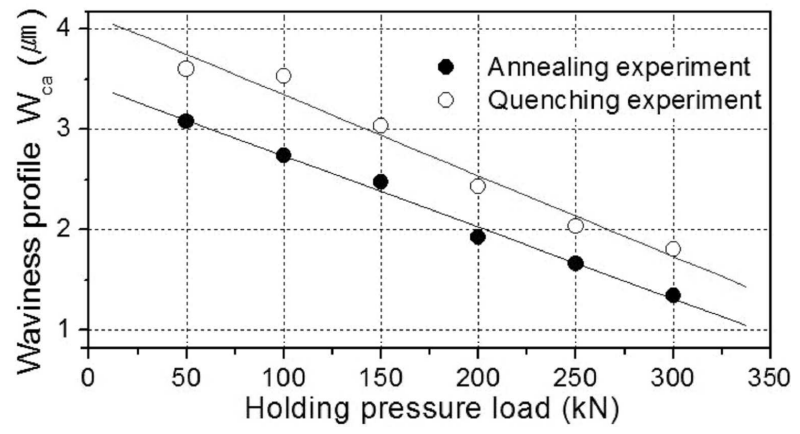

Fig. 3. Relationship between waviness profile and holding pressure load at mold temperature $80^{\circ} \mathrm{C}$.

During the annealing and quenching experiment, when mold temperature at demolding is $80^{\circ} \mathrm{C}$, the relationship between waviness profile and holding pressure load is shown in Fig. 3. Waviness profile is the one of surface defect, which is originated from the difference in shrinkage ratio in thickness direction between glass fiber reinforcement and polypropylene matrix during the cooling of moldings. It is known that glass fiber features smaller shrinkage compared with polypropylene. Waviness profile represents the degree of spherulite, fiber projection, crack, fiber exposure, micro-weldline, pinhole, etc. for $5 \mathrm{~mm}$ (width) $\times 30 \mathrm{~mm}$ (length) of moldings. Surface defects of moldings during mold cooling for compression molding of composite are spherulite, crack, etc. for annealing, and fiber exposure, micro weldline, etc. for quenching.

Quenching of mold cooling shows smoothness of molded surface compared with annealing. The reason for the better smoothness of moldings in case of annealing is elucidated by the larger surface unevenness value for fiber exposure, micro weldline, etc. from quenching than spherulite and crack from annealing process. Therefore, quenching does not assure the better surface characteristics.

From Fig. 3, waviness profile of moldings is measured, and higher holding pressure load improves the surface properties. Result of annealing and quenching experiment for holding pressure load is similar characteristics. Surface characteristics of moldings are dependent on holding pressure load rather than the effect of cooling rate.

Relationship between waviness profile $\left(W_{\text {ca }}\right)$ and holding pressure load $(P)$ during the annealing and quenching experiment in Fig. 3 can be denoted as Eqs. (2) and (3): 


$$
\begin{aligned}
& W_{\text {ca }}[\mu \mathrm{m}]=3.45-0.00713 \times P[\mathrm{kN}], \\
& W_{\text {ca }}[\mu \mathrm{m}]=4.15-0.00806 \times P[\mathrm{kN}]
\end{aligned}
$$

At the production environment for GFRP composites, 15-20 MPa of molding pressure is used during compression molding. Therefore, $100 \mathrm{kN}$ of holding pressure load is utilized to evaluate the impact of mold temperature during holding pressure and cooling.

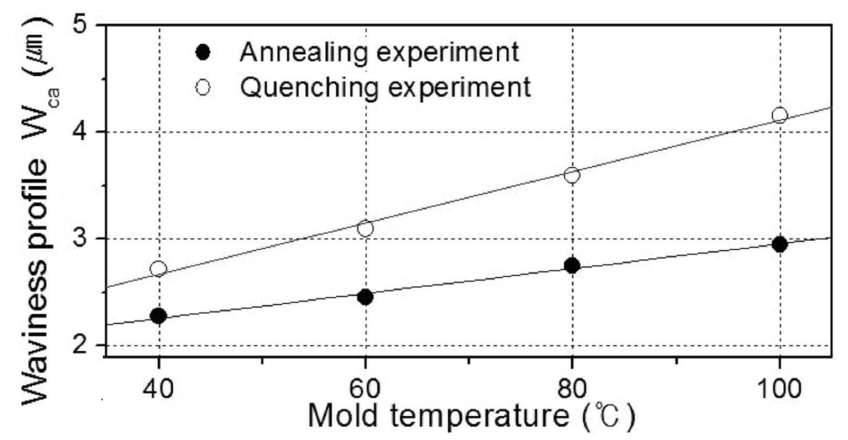

Fig. 4. Relationship between waviness profile and mold temperature at holding pressure load $100 \mathrm{kN}$.

Figure 4 shows the relationship between mold temperature and waviness profile at $100 \mathrm{kN}$ of holding pressure load. Lower mold temperature ensures the less waviness profile. As shown in Fig. 3, less waviness profile is achieved at annealing process. One of the reason for less waviness profile is the generation of fiber exposure, micro weldline, etc. is available only for quenching process.

From the measurement results for waviness profile in Fig. 4, surface characteristics of moldings are dependent on mold temperature rather than cooling rate. In addition, waviness profile during holding pressure and cooling process is related to the formation of surface unevenness, which is freely deformed due to the shrinkage of matrix. Fiber content in moldings of GFRP composites shows the greater deviation per unit volume. That is, waviness profile is generated where the composition difference is developed, and it is led to the different shrinkage ratio.

Relationship between waviness profile $\left(W_{\text {ca }}\right)$ and mold temperature $(T)$ at annealing and quenching experiment in Fig. 4 can be denoted as Eqs. (4) and (5):

$$
\begin{aligned}
& W_{\text {ca }}[\mu \mathrm{m}]=1.79-0.01163 \times T\left[{ }^{\circ} \mathrm{C}\right], \\
& W_{\text {ca }}[\mu \mathrm{m}]=1.71-0.02406 \times T\left[{ }^{\circ} \mathrm{C}\right] .
\end{aligned}
$$

From these results, preferable molding condition for smoothness of moldings during holding pressure and cooling of compression molding with GFRP composites is higher holding pressure load and lower mold temperature.

\section{Conclusion}

During the compression molding of GFRP composites, waviness profile for moldings, which are fabricated with different molding condition, is measured with surface profiler, and the following results are obtained.

(1) Measured waviness profile for the surface of moldings is smaller in case of annealing, higher holding pressure load, and lower mold temperature. In addition, surface roughness of moldings is dependent on holding pressure load than mold temperature.

(2) The equation that can estimate the waviness profile of surface quantitatively is proposed using the molding conditions, such as holding pressure load and mold temperature for compression molding of GFRP composites.

\section{Acknowledgments}

This study was supported by research fund from Chosun University, 2012.

\section{References}

[1] P. Lesiak, M. Szelag, K. Milenko, T.R. Wolinski, A.W. Domanski, K. Jedrzejewski, A. Boczkowska, , Acta Physica Polonica A 120, 698 (2011).

[2] J.W. Kim, J.J. Lee, D.G. Lee, J. Mater. Process. Technol. 201, 755 (2008)

[3] J.W. Kim, D.G. Lee, Trans. Nonferrous Met. Soc. China 21, 170 (2011)

[4] J.W. Kim, D.G. Lee, J. Nanosci. Nanotechnol. 10, $3650(2010)$

[5] H. Yaguchi, H. Hojo, D.G. Lee, E.G. Kim, J. Polym. Proc. Soc. 10, 262 (1995)

[6] J.W. Kim, H.S. Kim, D.G. Lee, Adv. Sci. Lett. 8, 682 (2012)

[7] J.W. Kim, H.S. Kim, D.G. Lee, Mater. Res. Innovations 15, 303 (2011) 